\section{INSTITUTZA ANE \\ FINANCIJE}

\title{
Državne potpore u Hrvatskoj: ipak se kreće
}

\author{
mr. sc. Marina Kesner-Škreb
}

Hrvatska izdvaja pet puta veći postotak BDP-a za državne potpore od prosjeka EU-a. Ipak brojke o subvencijama u usvojenom državnom proračunu za 2009. godinu ukazuju na želju za određenim pozitivnim pomacima. U tekstu koji slijedi izdvojit ćemo glavne naglaske iz najnovijeg Godišnjeg izvješća o državnim potporama za 2007. godinu Agencije za zaštitu tržišnog natjecanja ${ }^{1}$, te iz usvojenog državnog proračuna za 2009. godinu. ${ }^{2}$

U Hrvatskoj je tijekom 2006 i 2007. godine naglo poraslo ukupno državno podupiranje gospodarstva. Državne su potpore u 2007. godini gotovo 4 milijarde kuna ili $77 \%$ veće od onih 2005. godine, a najviše su porasle, odnosno udvostručile su se potpore industriji i uslugama. No niti rast potpora poljoprivredi nije zanemariv, te se za poljoprivredu odvaja $50 \%$ više sredstva 2007. godine nego li dvije godine ranije. Raste i udio državnih potpora u BDP i to s 2,2 na 3,3\%, a svaki zaposleni 2007. godine odvaja za državne potpore oko 6.000 kuna ili preko dvije trećine više nego li 2005. godine.

Tablica 1. Ukupne državne potpore u Hrvatskoj 2005-2007. godine

\begin{tabular}{|c|c|c|c|c|c|c|}
\hline & \multicolumn{3}{|c|}{ Milijuna kuna } & \multicolumn{3}{|c|}{ Godišnja stopa promjene (\%) } \\
\hline & 2005. & 2006. & 2007. & $\begin{array}{l}2006 / \\
2005 .\end{array}$ & $\begin{array}{l}2007 / \\
2006 .\end{array}$ & $\begin{array}{l}2007 / \\
2005 .\end{array}$ \\
\hline Poljoprivreda i ribarstvo & $2.124,7$ & $2.535,5$ & $3.210,2$ & 19,3 & 26,6 & 51,1 \\
\hline Industrija i usluge & $2.932,7$ & $5.374,4$ & $5.737,2$ & 83,3 & 6,8 & 95,6 \\
\hline UKUPNO & $5.057,4$ & $7.909,9$ & $8.947,4$ & 56,4 & 13,1 & 76,9 \\
\hline \multirow{2}{*}{$\begin{array}{l}\text { Udio ukupnih državnih potpora u } \\
\text { BDP-u, (\%) } \\
\text { Ukupne potpore po zaposlenom, } \\
\text { (HRK) }\end{array}$} & 2,2 & 3,2 & 3,3 & & & \\
\hline & $3.560,1$ & $5.388,6$ & $5.898,5$ & & & \\
\hline
\end{tabular}

Izvor: autoričin izračun na temelju Godišnjeg izvješća AZTN-a.

\footnotetext{
${ }^{1}$ Hrvatski je Sabor na sjednici 5. prosinca 2008. godine usvojio Godišnje izvješće o državnim potporama za 2007. godinu koje mu je uputila Agencija za zaštitu tržišnog natjecanja (AZTN) u čijoj je nadležnosti odobravanje, nadzor i povrat državnih potpora. Izvješće je dostupno na http://www.aztn.hr/pdf/izvjesca/ godisnje izvijesce DP 2007.pdf.

2 Državni proračun za 2009. godinu usvojen je u Saboru 15. prosinca 2009. godine i dostupan je na http://www.sabor.hr/Default.aspx?art=25631.
} 
Do porasta državnih potpora dolazi posebno 2006. godine i to zbog sanacije brodogradnje, te potpora Hrvatskim željeznicama. Tako je u rujnu 2006. godine u «paketu» za sanaciju brodogradilišta odobreno 4,2 milijarde kuna potpora u obliku državnih jamstava, s tim da je do kraja 2006. godine realizirano državnih jamstava u iznosu od 1,55 milijardi kuna, a 2007. godine 1,7 milijardi kuna. Drugi razlog porasta ukupnih državnih potpora jest promjena zakonske regulative kojom se liberalizira željeznički promet, a koja je stupila na snagu 1. siječnja 2006. godine3. Nakon tog datuma formalno prestaje monopolski tržišni status Hrvatskih željeznica, te se državna sredstva dodijeljena ovom sektoru počinju smatrati državnom potporom, što do tada nije bio slučaj. Tako potpore Hrvatskim željeznicama rastu s nule 2005. godine na 822 milijuna kuna 2006. godine, te na 906 milijuna kuna 2007. godine.

\section{Što su državne potpore ${ }^{4}$}

Prema definiciji EU-a, državnom se potporom smatra potpora:

1. koja je dodijeljena iz državnih sredstava;

2. koja pruža ekonomsku prednost određenom poduzeću, sektoru ili regiji;

3. koja je selektivna jer narušava ravnotežu između poduzeća i njihove konkurencije;

4. koja utječe na konkurentnost i trgovinu između zemalja članica.

Državne potpore se dijele na horizontalne (namijenjene svim poduzećima u gospodarstvu), sektorski usmjerene (izabranim poduzećima), regionalne te za poljoprivredu i ribarstvo. Potpora se može dodijeliti putem različitih instrumenta: subvencija, poreznih olakšica, udjela u vlasničkom kapitalu, povoljnih kredita, poreznih dugova, jamstava i sl.

Struktura državnih potpora u promatrane tri godine se pogoršava u tom smislu da je prepolovljen udio horizontalnih potpora u ukupnim potporama. Horizontalne potpore namijene su svim poduzetnicima i sektorima, te u znatno manjoj mjeri narušavaju tržišno natjecanje od sektorskih potpora koje se dodjeljuju određenom poduzetniku ili pak sektoru. Europska unija posebno favorizira horizontalne potpore i sintagma «manje, ali kvalitetnije potpore» koja se provlači kroz glavne dokumente Europske unije odnosi se upravo na poticanje država članica za razvojem horizontalnih potpora. Dakle, u Hrvatskoj se trebaju uložiti napori da se preokrene trend horizontalnih potpora te da država potiče ulaganja u istraživanje i razvoj, zaštitu okoliša, male i srednje poduzetnike, i sl.

Tablica 2. Sektorska struktura državnih potpora (bez poljoprivrede)

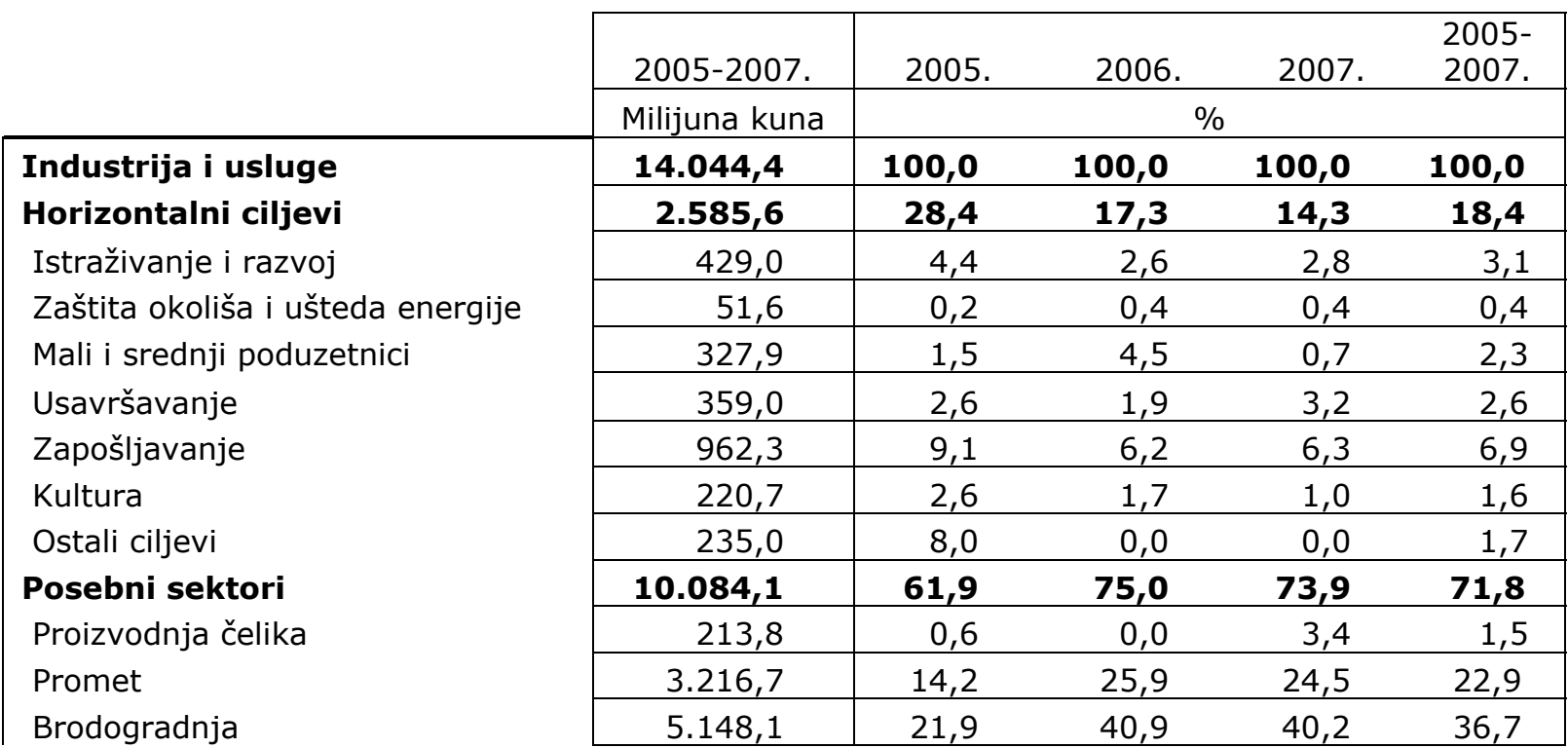

${ }^{3}$ Zakon o željeznici (NN123/03, 194/03 i 30/04) i Zakon o podjeli trgovačkog društva HŽ-Hrvatske željeznice d.o.o. (NN153/05).

${ }^{4}$ Detaljnu definiciju vidjeti u Izvješću AZTN-a: http://www.aztn.hr/pdf/izvjesca/godisnje izvijesce DP 2007.pdf. 
Turizam

Ostali sektori

Sanacija i restrukturiranje

Regionalne potpore

Potpore na lokalnoj razini

\begin{tabular}{|r|rrrr|}
\hline 621,4 & 6,2 & 4,9 & 3,1 & 4,4 \\
\hline 262,8 & 1,9 & 3,1 & 0,7 & 1,9 \\
\hline 621,2 & 17,1 & 0,2 & 1,9 & 4,4 \\
\hline $\mathbf{9 1 2 , 2}$ & $\mathbf{5 , 1}$ & $\mathbf{5 , 3}$ & $\mathbf{8 , 4}$ & $\mathbf{6 , 5}$ \\
\hline $\mathbf{4 6 2 , 5}$ & $\mathbf{4 , 6}$ & $\mathbf{2 , 5}$ & $\mathbf{3 , 4}$ & $\mathbf{3 , 3}$ \\
\hline
\end{tabular}

Izvor: autoričin izračun na temelju Godišnjeg izvješća AZTN-a.

Istovremeno $\mathrm{s}$ padom horizontalnih potpora raste udio podupiranja posebnih sektora za dvanaest strukturnih poena, tj. od ukupnih potpora udio sektorskih raste sa $62 \%$ ukupnih potpora (bez poljoprivrede) 2005. na 74\% 2007. godine. Porast sektorskih potpora izravna je posljedica porasta podupiranja prometa i brodogradnje, te od $10 \mathrm{mlrd}$. kuna sektorskih potpora dodijeljenih u razdoblju 2005-07. čak 8,3 mlrd. kuna odlazi na ova dva sektora. Tako na promet i brodogradnju otpada $83 \%$ svih potpora, a ostatak od samo $17 \%$ odlazi na podupiranje svih ostalih sektora gospodarstva.

Kontinuirano raste udio regionalnih potpora koje služe poticanju gospodarskog razvitka manje razvijenih područja, a dodjeljuju se uglavnom putem poreznih olakšica. Zajedno s potporama koje se dodjeljuju na lokalnoj razini one u razdoblju 2005-07. godina čine oko $9 \%$ svih potpora.

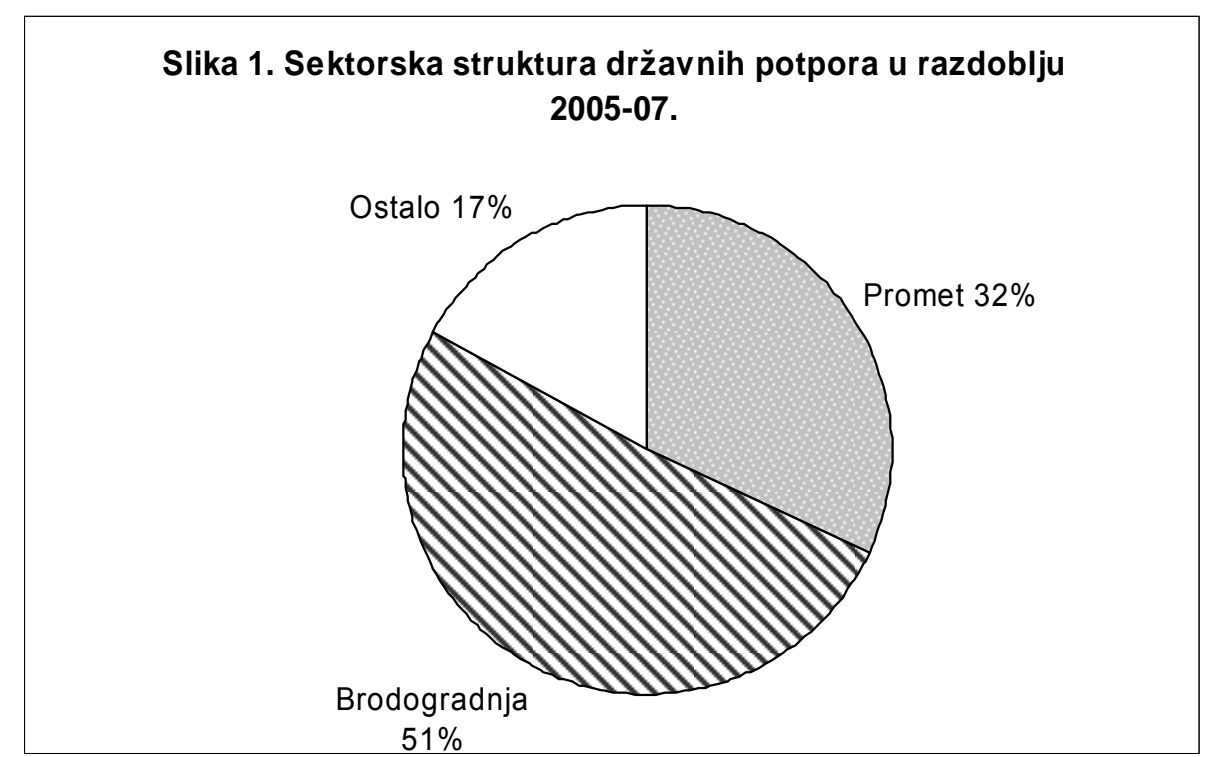

Izvor: autoričin izračun na temelju Godišnjeg izvješća AZTN-a.

U Hrvatskoj se podupiranje gospodarstva najčešće provodi korištenjem subvencija ( $58 \%$ 2007. godine) i državnih jamstava (25\% 2007. godine). Na području poljoprivrede i ribarstva prevladavaju subvencije, dok se za sektorske državne potpore najčešće koriste državna jamstva koja su najzastupljenija kod brodogradnje. Na trećem mjestu su porezne olakšice i izuzeća, dok se udjeli u vlasničkom kapitalu i povoljni zajmovi najmanje koriste. 


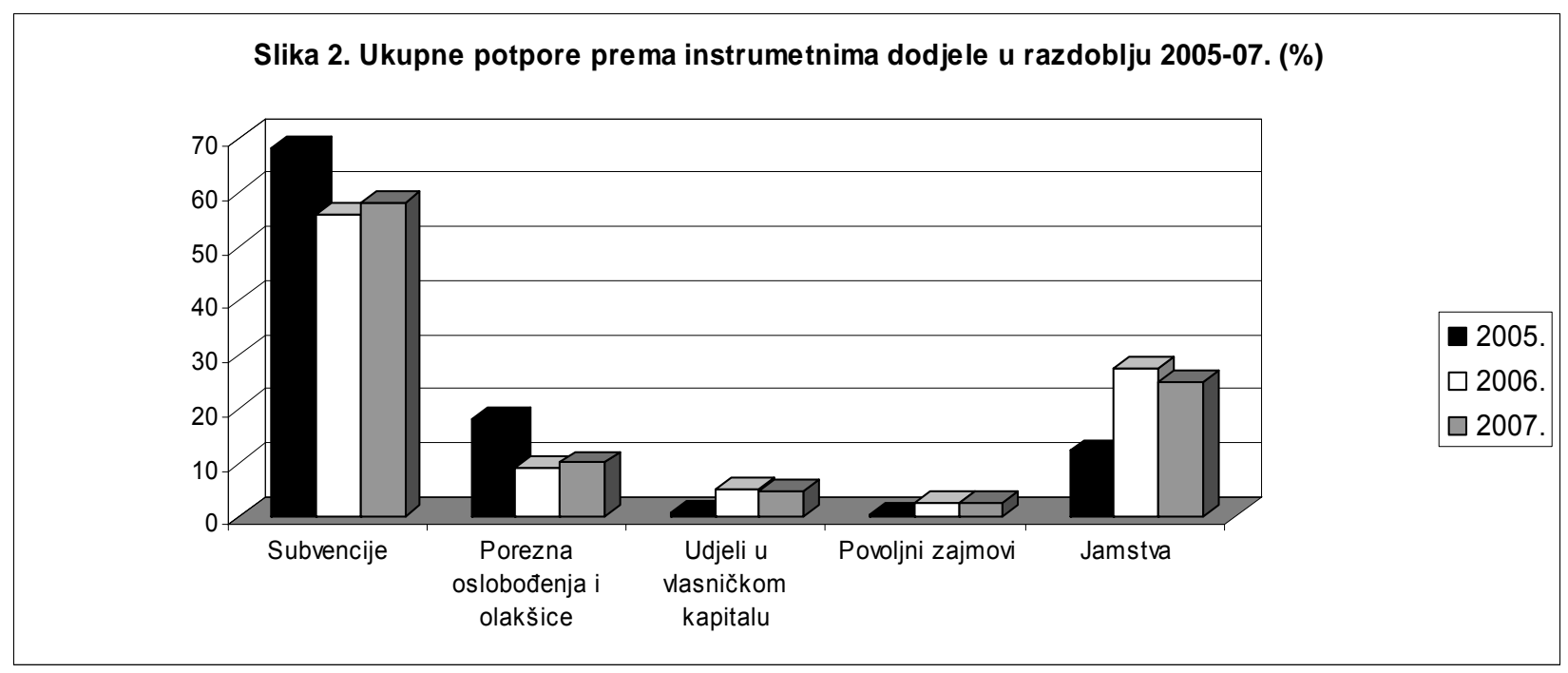

Izvor: autoričin izračun na temelju Godišnjeg izvješća AZTN-a.

U EU na državne potpore najviše troši Malta, koja izdvaja 2,3\% BDP-a, a najmanje Velika Britanija, samo 0,2\% BDP-a ${ }^{5}$. Cijela EU u prosjeku izdvaja $0,6 \%$, a nove države članice $0,9 \%$ BDP-a. Hrvatska premašuje sve navedene udjele i s 3,1\% BDP-a peterostruko više izdvaja za državne potpore od prosjeka Europe.

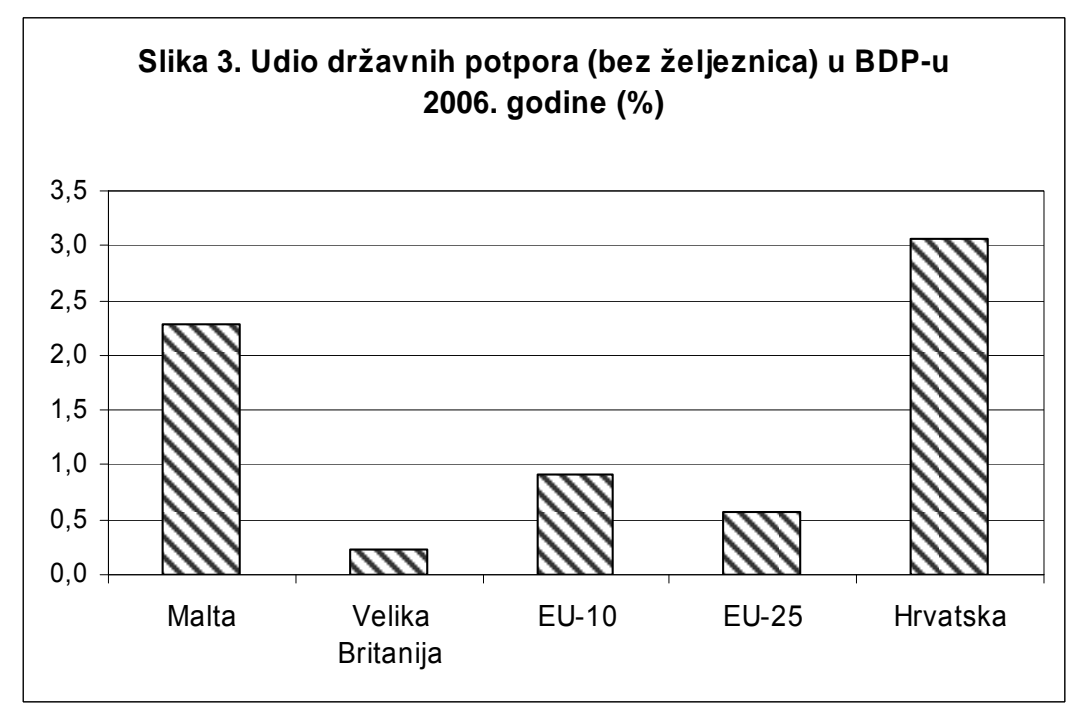

Izvor: autoričin izračun na temelju Godišnjeg izvješća AZTN-a.

No upravo donesen državni proračun za 2009. godinu ukazuje na neke pomake u kretanju subvencija, glavnog instrumenta dodjele državnih potpora. Naime nakon snažnog rasta 2007. i 2008. godine od 14,5 odnosno $13,8 \%$, za slijedeću godinu predviđeno je smanjivanje subvencija koje se dodjeljuju putem državnog proračuna za $6,7 \%$ ili za oko 500 milijuna kuna. Ohrabrujuće je da opada subvencioniranje velikih korisnika državne pomoći: brodogradnje i Hrvatskih željeznica. Prema projekcijama za 2010. i 2011. godinu, subvencije bi se u slijedećem razdoblju trebale zadržati na otprilike razini onih iz 2009. godine. Vrijeme će uskoro pokazati znače li ovakve promjene preokretanje trenda ili će se država vratiti podupiranju kroničnih hrvatskih gubitaša. Promjene koje donosi pristupanje Hrvatske EU predstavljat će snažan vanjski čimbenik napuštanju politike pomaganja tekućeg poslovanja dugogodišnjih gubitnika i preusmjeravanje potpora na bitne i toliko nužne strukturne reforme.

\footnotetext{
${ }^{5}$ Uspoređuju se državne potpore bez željeznice kako se uobičajeno prikazuju u EU.
} 
Tablica 3. Subvencije u državnom proračunu za 2009. godinu

\begin{tabular}{l|rr|r|r|r|r|}
\cline { 2 - 6 } & $\begin{array}{c}\text { Ostvarenje } \\
\text { 2007. }\end{array}$ & $\begin{array}{c}\text { Proračun } \\
\text { za 2008. }\end{array}$ & $\begin{array}{c}\text { Prijedlog } \\
\text { za 2009. }\end{array}$ & $\begin{array}{c}\text { Projekcija } \\
\text { za 2010. }\end{array}$ & $\begin{array}{c}\text { Projekcija } \\
\text { za 2011. }\end{array}$ \\
\hline PRORAČUNSKI RASHODI (mln. kn) & $\mathbf{1 0 8 . 0 0 7}$ & $\mathbf{1 1 7 . 2 6 2}$ & $\mathbf{1 2 3 . 3 9 6}$ & $\mathbf{1 3 1 . 8 0 0}$ & $\mathbf{1 3 8 . 4 7 0}$ \\
\cline { 2 - 7 } $\begin{array}{l}\text { SUBVENCIJE (mln. kuna) } \\
\text { Godišnja stopa promjene, (\%) }\end{array}$ & $\mathbf{6 . 4 9 2}$ & $\mathbf{7 . 3 9 1}$ & $\mathbf{6 . 8 9 5}$ & $\mathbf{6 . 9 3 4}$ & $\mathbf{6 . 8 3 6}$ \\
\cline { 2 - 7 } $\begin{array}{l}\text { Udio subvencija u ukupnim } \\
\text { proračunskim rashodima, (\%) }\end{array}$ & 14,5 & 13,8 & $-6,7$ & 0,6 & $-1,4$ \\
\cline { 2 - 7 } & & & & & \\
\hline
\end{tabular}

Izvor: autoričin izračun na temelju Državnog proračuna za 2009. 